\title{
Barriers to adoption of RPAs on construction projects: a task-technology fit perspective
}

\author{
Hamed Golizadeh \\ DesignandBuiltEnvironmentSchool,UniversityofCanberra, Canberra, Australia \\ M.RezaHosseini \\ SchoolofArchitectureandBuiltEnvironment,DeakinUniversity, Geelong, Victoria, Australia \\ David John Edwards \\ FacultyofComputing, EngineeringandtheBuiltEnvironment(CEBE), Birmingham City University, Birmingham, UK \\ Sepehr Abrishami \\ SchoolofCivilEngineeringandSurveying, UniversityofPortsmouth, Portsmouth, UK \\ Nasrin Taghavi \\ University of Tabriz, Tabriz, Iran, and \\ Saeed Banihashemi \\ DesignandBuiltEnvironmentSchool,UniversityofCanberra, Canberra, Australia
}

\begin{abstract}
Purpose - Extant literature extensively articulates the advantages of using remotely piloted aircrafts (RPAs) in a myriad of construction activities. Yet, the barriers that hinder their wider adoption on construction projects have received scant academic attention. This study aims at addressing this gap in the literature.

Design/methodology/approach - This study reviews 59 papers published on the use of RPAs for construction activities and offers an evaluation of barriers to widespread adoption throughoutthe sector.

Findings - Barriers are identified, collated and categorized into five thematic groups, namely, technical difficulties, restrictive regulatory environment, site-related problems, weather and organizational barriers.

Practical implications - The paper contributes to knowledge by: signposting a need for reordering priorities when defining future research on RPAs, suggesting measures to address the barriers identified and providing pragmatic guidance for construction companies intending to use RPAs on their projects.

Originality/value - Using the task-technology fit theory, the study uncovers that current RPA technology is an under-fit match for construction activities and represents a prominent barrier to adoption. This is a dissenting finding, given that past studies on RPAs have primarily focused upon addressing public acceptance, concerns and societal consequences. Enablers of the identified barriers are also collated from extant literature and contemporary practice and encapsulated in a conceptual model.
\end{abstract}

Keywords: Adoption, Drone, Construction industry, Civil engineering, UAV, Barrier 


\section{Introduction}

Remotely piloted aircrafts (RPA) are unmanned aerial vehicles (UAVs) that are used for commercial purposes (CASA, 2016). UAVs, popularly known as drones, can be simply defined as: "any aerial vehicle that does not rely on an on-board human operator for flight, either autonomously or remotely operated" (Rao et al., 2016, p. 84). Given the technological advancements on miniaturization of components; the availability of smaller, lighter and cheaper aircrafts; and increased capabilities, RPAs will secure a significant share in various industrial market sectors (Pádua et al., 2017; Li and Liu, 2018). For example, industry reports indicate that global markets will reach US\$2.8bn by 2018 and to US\$4.8bn in 2021, thanks to the availability of devices, with less cost and more versatility (Market Research Store, 2012; Anastasios et al., 2018). Furthermore, RPAs are predicted to become the most dynamic sector of growth for the global aerospace industry (Zaloga, 2011; Canis, 2015). Top applications of RPAs include their widespread usage as military weapons, aerial photography, shipping and delivery and disaster management (Clarke, 2014a). RPAs have been also successfully utilized in the construction sector for facilitating site layout planning, remote observation of construction progress, site inspection and safety monitoring (Ham etal., 2016; Melo etal., 2017). Moreover, using building information modeling (BIM) on projects has reached an acceptable level of maturity, opening a new avenue for integrating BIM with visual data collected through RPAs (Han and Golparvar-Fard, 2017). The physical size or value of a construction project is not a delimiting factor, as even small-scale construction projects are capable of benefiting from RPAs in various forms - such as creating high-resolution 3D models to be shared online with clients and owners (McPartland, 2017; John et al., 2018).

Despite their broad potential and strong promotion within academic discourse, RPAs have not been widely adopted across the construction industry due to a plethora of barriers (Dupont et al., 2017; McCabe et al., 2017). For example, recent studies suggest that the key barriers include stringent aviation regulations exacerbated by public concerns that RPAs are being used ostensibly as surveillance equipment (Karpowicz, 2017a; McMinn, 2017). Similarly, their commercial use has been criticized by both individuals and activist organizations around issues relating to informational integrity and privacy (Luppicini and So, 2016; Rao et al., 2016). However, literature also reveals that the barriers to widespread use of RPAs remain an underresearched area within a construction context (Lidynia et al., 2017), and that existing studies have too narrow a focus: Gevaert et al. (2018) targeted societal barriers, Clarke (2014a) examined regulation-related aspects, Pärn and Edwards (2017) referenced applications in laser scanning, Li and Liu (2018) discussed various applications of multirotor-type RPAs and Zhou and Gheisari (2018) discussed various types of sensors and RPAs for construction activities; recently, Greenwood et al. (2019) conducted a review on applications of RPA on infrastructure projects.

With the above in mind, the barriers to adoption of RPAs in the construction context

represent a real problem. According to Müller-Bloch and Kranz (2015), the term research problem - and the ensuing call for action/resolution - can also be applied interchangeably with the term research gap. This research problem - gap - acts as an input for defining review studies; it triggers further research, with the aim of characterization, verification and presentation of the gap through synthesizing the literature (Müller-Bloch and Kranz, 2015).

Consequently, this paper seeks to stimulate a wider academic discourse by:

- $\quad$ identifying the barriers that hinder widespread adoption of RPAs in contemporary practice; and

- defining and delineating the current state (and possible future) of RPAs deployment within the construction industry. 


\section{Applications and innovations}

Nearly one-and-a-half centuries after Montgolfier brothers designed the first widely known manned flight (a hot air balloon), the Hewitt-Sperry Automatic Airplane in 1916 was demonstrated as the first modern UAV (Zaloga, 2011). UAVs were initially developed for carrying weapons and explosives as early as 1915 in the USA and as targets around 1930 in the UK (Clarke, 2014b). However, these decommissioned military devices have found alternative uses and applications within civilian society. According to the Civil Aviation Safety Authority of Australia (CASA, 2016), UAVs can be categorized into two types:

1. RPAs which are used for government, commercial or research purposes; and

2. model aircrafts used only for entertainment, in sport and recreation activities.

The distinction between the two is that, for a model aircraft, no fee is paid for the service (Clarke, 2014b). Consequently, RPAs represents terminology applicable to the commercial purposes on construction sites and is used within this study. For a further and more exhaustive treatment of terminologies and the various methods of UAVs classification, interested readers should consult with Clarke (2014b).

The fastest commercial growth opportunity for RPAs comes from business with an expected value of US\$13bn sales expenditure between 2016 and 2020 (Goldman Sachs, 2016). Of this, the largest market share of up to US\$11bn resides within the construction industry (Goldman Sachs, 2016; McPartland, 2017). RPAs have been extensively used in construction projects (Alsafouri and Ayer, 2018) for activities such as: creating 3D models of sites, measurements, monitoring of progress and surveying of earthworks inspections (Cole and Creech, 2016; Ham et al., 2016; Irizarry and Costa, 2016). RPAs have also been used to enhance safety on construction sites (Seo et al., 2015; Irizarry and Costa, 2016; Melo et al., 2017; Alsafouri and Ayer, 2018) and have been integrated with BIM to create a new innovative application of the technology (Teizer, 2015; Hamledari et al., 2017b; Han and Golparvar-Fard, 2017). RPAs have also been used for the quality inspection of buildings, facades, bridges and culverts (Serrano, 2011; Landes et al., 2012; Roca et al., 2013; Morgenthal and Hallermann, 2014; Ellenberg et al., 2016b; Rakha et al., 2018). Inspection tasks are extensive and range from damage quantification of bridge structures (Ellenberg et al., 2016b; Omar and Nehdi, 2017) to use of heat mapping technology for accurate energy audits that seek to maximize energy savings and improvements in building envelopes (Rakha et al., 2018). RPAs are increasingly utilized for monitoring and inspection of buildings that are remarkable in terms of size and architecture this is because of an increased focus on sustainability and resource efficiency in the building and infrastructure sector that necessitates extending the operational lifetime of constructed facilities (Vacca et al., 2017; John et al., 2018). In summary, the applications of RPAs within academic literature are considerable, but the practical applications within industry would grow further if the barriers hindering their widespread use are addressed (Luppicini and So, 2016).

\section{The theoretical lens: task-technology fit}

Technological innovations per se are of little value unless accepted and utilized within industry and society (Hosseini et al., 2015; Gledson, 2016). Identifying the reasons preventing the acceptance of technological innovation paves the way forward for promoting its usage and tackling the barriers that hinder its widespread application among the target population (Samaradiwakara and Gunawardena, 2014; Mollaoglu et al., 2016). According to innovation diffusion theory, adoption of any technological innovation is stifled by some barriers like resistance from consumers, among others (Rogers, 2010). A fine-grained 
approach is essential when exploring the barriers to adoption of technological innovations (Antioco and Kleijnen, 2010).

The technology acceptance model (TAM) and the task-technology fit model (TTF) represent two significant models for explaining user acceptability of technological innovations (Dishaw and Strong, 1999; Imoudu Enegbuma et al., 2014). TAM has been criticized for weakness in terms of its lack of task focus - that is, robustly evaluating the technological innovation acceptance, use and performance, as argued by Dishaw and Strong (1999). Conversely, TTF developed by Goodhue (1995) has been widely used to successfully explain the factors that affect the adoption of technological innovations (Junglas etal., 2008):

- investigate software maintenance systems (Dishaw and Strong, 1998);

- investigate group support systems (Zigurs and Buckland, 1998; Dishaw and Strong, 1999); and

- evaluate performance factors of an integrated information center on end-users (Goodhue, 1997; Goodhue et al., 1997).

Specifically, TTF is not reliant upon historical information on the use of the technological innovations (Schlauderer et al., 2016) and is therefore, more suitable for RPAs that do not have a long history of use.

TTF can be assessed as a trichotomous variable, namely: "ideal-fit", "under-fit" and "over-fit" (Junglas et al., 2008). Ideal-fit indicates an exact match between task requirements and the functionality of a technological innovation. Over-fit occurs when more functionality is provided than is required, and under-fit reflects situations in which technological innovation is not capable of: "facilitating solving the problem at hand in an ideal manner" (Junglas et al., 2008, p. 1050).

\section{Research methods}

Data for systematic reviews are available from databases such as the Web of Science (WoS), PubMed, Google Scholar and Scopus. Of these, Scopus was selected because it has a wider range of coverage, faster indexing process and lists more recent publications (Hosseini et al., 2018). To identify pertinent keywords, it should be acknowledged that various terms are commonly used in referring to RPAs across the construction industry. For example, the Federal Aviation Administration of the USA uses remotely piloted vehicles (RPVs) and RPA. In the UK, the term remotely piloted air system (RPAS), UAV and drone are preferred (Fishpool, 2010; Herlik, 2010; Marchant et al., 2015). The Civil Aviation Safety Authority in Australia shifted from using the terms UAV and drone to RPAs, and unmanned aircraft systems (UASs) (CASA, 2016). Together, these homogeneous terminologies were used as keywords for identifying relevant research studies associated with RPAs within Scopus. The search had no time limitation, with the date range set to "all years to present". The document type was refined to filter only articles published in journals; the rationale being that journal articles represent the most influential research studies. Conference papers are published in large numbers, and little is gained by including them, given the extra level of complexity added to the analyses (Butler and Visser, 2006). Keywords were searched on abstract/title/keywords. The preliminary outcome comprised of 11,672 studies related to RPAs published from February 2005 to October 5, 2017. The search was further narrowed to publications relevant to the construction industry. The findings were limited to those studies having the term "construction" in the abstract/title/keywords, whereas terms such as chemistry, bio-chemistry, agriculture, medicine and nursing were excluded from the search. This filtering reduced the pool of studies down to 299. However, because the term 
"construction" carries an ambiguous quality (being used to describe the manufacture of aircraft, as well as the industry more broadly), further refining was needed. Thus, the abstracts of all 299 studies were reviewed manually and those dealing with the manufacture or design of aircraft/components were omitted from the list. The outcome of this three-tiered filtering process produced a final list of 59 journal articles that clearly discuss RPAs in the construction industry. These articles provided multiple sources of information and were utilized to determine the barriers to the use of RPAs within construction practice. Once the existing barriers are mapped, this study will look at fitness criteria required for RPAs usage in the context of construction projects. This allows to determine whether RPAs are ideal-fit, under-fit and over-fit based on the definitions provided by Goodhue and Thompson (1995). It is noted that a technological innovation will have a constructive influence on performance if, and only if, it is applied and the functions granted by the technology fit the task. The last step of the analysis is to provide solutions for the identified barriers that make the RPAs under-fit or over-fit for the current practice requirement of the industry. These solutions are provided based on the collected 59 articles, as well as existing research studies on RPAs in other industries, specifically research from the aviation industry. Figure 1 illustrates the research design and the sequence of activities.

\section{Barriers to adoption of RPAs}

The major barriers and various dimensions associated with each dimension are tabulated in

Table 1; these barriers are thematically grouped into five categories by: technical difficulties, restrictive regulatory environment, site-related problems, weather and organizational barriers.

The technical difficulty category deals with the shortcomings associated with the operating system of RPAs, as well as the technical flaws RPAs in performing specific tasks. Restrictive regulatory environment points to the regulations that restrict using and applying RPAs for various tasks. Site-related barriers present problems that are specific to the operation of RPAs on construction sites, while weather category describes the weather conditions that affect or prevent the operation of RPAs. Lastly, organizational barriers present difficulties that affect the adoption of RPAs, stemmed from business considerations within constructioncompanies.

\section{Technical difficulties}

Land surveying and inspection tasks conducted by RPAs produce large-sized images/videos and, consequently, require a reliable and efficient transferring platform and storageprocess (Irizarry and Costa, 2016; Han and Golparvar-Fard, 2017). Typical methods are wireless platforms such as MICA, MICA2, MICAz or Imote2 for sending real-time data to a host base station (Kurata et al., 2005; Lynch and Loh, 2006; Maqbool and Sabeel, 2013). Loss of such a large volume of data is a major concern in wireless transferring platforms where the range of data loss may vary between 30 and 50 per cent (Yang and Nagarajaiah, 2017). Data loss can also occur due to failure in the documentation process (Kim et al., 2016). Storing large data can be problematic for construction companies, as this requires a "systematic" storage process approach, where practitioners struggle to avoid "drowning in drone data" (Karpowicz, 2017b). External hard drives are relatively low-cost, provide an affordable data storage and exchange solution within construction offices. However, exchanging bulk volumes of data among offices in different locations is still prone to various problems such as security concerns (Karpowicz, 2017b). Current data compression methods provide an unconvincing solution for such problems, because a high compression rate can create data reconstruction errors (Yang and Nagarajaiah, 2017). 
Step 1: Clarify the problem

Barriers remain a problem $\rightarrow$ A gap exists to drive further research

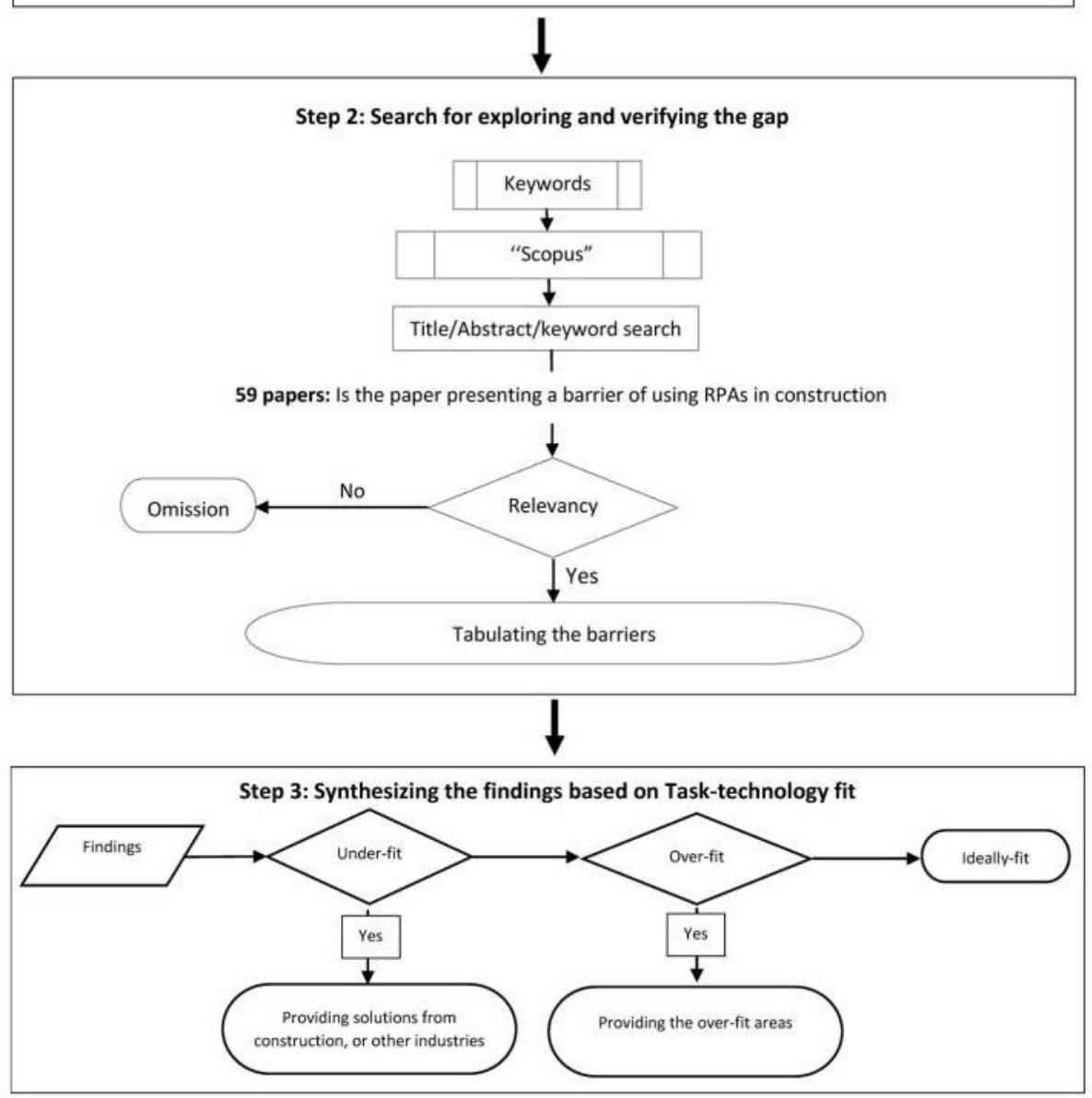

Figure 1. Research design

Loss or interference of GPS signals of RPAs within a building's interior or within the vicinity of densely populated buildings and/or high-rise buildings can lead to losing control of RPAs (Ham et al., 2016). Due to the ensuing erroneous positioning, RPAs can travel in any direction or location outside the predefined path and step outside the scope of the radio link, resulting in the consequent loss of the aircraft. Indeed, controlled flight via GPS signals is deemed to be a high-risk activity in public areas or spaces. Moreover, Morgenthal and Hallermann (2014) indicated that a GPS-driven RPA can experience loss of calibration on magnetometer sensors when entering close proximity to steel components - rendering the technology unsafe for an industry that is heavily reliant upon steel components within structures. Because of these aforementioned difficulties, Kim et al. (2016) argue that RPA 
Table 1. Barriers to adoption of RPAs in the construction industry

\begin{tabular}{|c|c|c|}
\hline Category & Barrier & Reference \\
\hline \multirow[t]{9}{*}{$\begin{array}{l}\text { Technical } \\
\text { difficulties }\end{array}$} & $\begin{array}{l}\text { Large volume of the } \\
\text { generated data and data loss }\end{array}$ & $\begin{array}{l}\text { Irizarryand Costa (2016), Kimetal. (2016), Hamledari } \\
\text { et al. (2017a), Han and Golparvar-Fard (2017), } \\
\text { Karpowicz (2017b), Yang and Nagarajaiah (2017) }\end{array}$ \\
\hline & $\begin{array}{l}\text { Failure of GPS signals } \\
\text { Inefficient flight paths }\end{array}$ & $\begin{array}{l}\text { Morgenthal and Hallermann (2014), Ham et al. (2016) } \\
\text { Irizarry and Costa (2016), Kimetal. (2016), Torres etal. } \\
\text { (2016) }\end{array}$ \\
\hline & $\begin{array}{l}\text { Lack of accuracy in detectingon } \\
\text { site dynamics Lack of } \\
\text { communication with human } \\
\text { objects }\end{array}$ & Ham etal. (2016), Wang etal. (2016) \\
\hline & Limited flight duration & $\begin{array}{l}\text { Irizarry et al. (2012), Morgenthal and Hallermann } \\
\text { (2014), OpferandShields (2014), Munoz-Morera etal. } \\
\text { (2015), Ellenberg etal. (2016b), Fangetal. (2016), Kim } \\
\text { et al. (2016), Leahy et al. (2016), Moud and Gheisari } \\
\text { (2016), Torres etal. (2016), Hassanalian and Abdelkefi } \\
\text { (2017), Yang and Nagarajaiah(2017) }\end{array}$ \\
\hline & Limited payload & $\begin{array}{l}\text { Eschmann et al. (2012), Liu etal. (2014), Morgenthal and } \\
\text { Hallermann (2014), Siebert and Teizer (2014), Ellenberg } \\
\text { et al. (2016a), Leahy et al. (2016) }\end{array}$ \\
\hline & $\begin{array}{l}\text { Low resolution of the } \\
\text { captured images }\end{array}$ & Li et al. (2016), Wang et al. (2016) \\
\hline & Positioning system inaccuracies & $\begin{array}{l}\text { Siebertand Teizer(2014), Lietal. (2016), Reaganetal. } \\
\text { (2016) }\end{array}$ \\
\hline & User-friendliness & Kim et al. (2016), Luppicini and So (2016) Vibrations \\
\hline & of the mounted camera & Ellenberg et al. (2016a), Reagan et al. (2016) Aircraft \\
\hline \multirow{7}{*}{$\begin{array}{l}\text { Restrictive } \\
\text { regulatory } \\
\text { environment }\end{array}$} & traffic restrictions & $\begin{array}{l}\text { Irizarry and Costa (2016), Kimetal. (2016), Stöcker etal. } \\
\text { (2017) }\end{array}$ \\
\hline & Restrictive national regulations & $\begin{array}{l}\text { Morgenthal and Hallermann (2014), Blinn and Issa } \\
\text { (2016), Herrmann (2016), Ka,cuni,c et al. (2016), Kim et al. } \\
\text { (2016), Stöcker et al. (2017), Anastasios et al. (2018), CASA } \\
\text { (2018) }\end{array}$ \\
\hline & Certifications for pilot and flight & $\begin{array}{l}\text { Irizarry et al. (2012), Opfer and Shields (2014), Blinn } \\
\text { andlssa (2016),Boudreau (2016),Kim etal. (2016), } \\
\text { CASA (2018) }\end{array}$ \\
\hline & Insurance issues & Boudreau (2016), Herrmann (2016), Thelander (2017) \\
\hline & Privacy issues & $\begin{array}{l}\text { Jordan (2015), Boudreau (2016), Costa etal. (2016), } \\
\text { Herrmann (2016), Kim etal. (2016), Luppiciniand So } \\
\text { (2016), Lidynia et al.(2017) }\end{array}$ \\
\hline & Public safety & $\begin{array}{l}\text { Opfer and Shields (2014), Siebert and Teizer (2014), } \\
\text { Clothier etal. (2015), Boudreau (2016), Ka,cuni,cetal. } \\
\text { (2016), Kim et al. (2016), Luppicini and So (2016), } \\
\text { Anastasios et al. (2018), John et al. (2018) }\end{array}$ \\
\hline & Accidents & $\begin{array}{l}\text { Morgenthal and Hallermann (2014), Clothier etal. } \\
\text { (2015), Jordan (2015), Costa et al. (2016), ATSB (2017), }\end{array}$ \\
\hline Site-related & & Lidynia et al. (2017), John et al. (2018) \\
\hline problems & $\begin{array}{l}\text { Interferences with project activities } \\
\text { Obstacles on construction sites }\end{array}$ & $\begin{array}{l}\text { Costa et al. (2016), Anastasios et al. (2018) } \\
\text { Boudreau (2016), Irizarryand Costa (2016), Kimetal. } \\
\text { (2016), John et al. (2018) }\end{array}$ \\
\hline Weather & $\begin{array}{l}\text { The RPAs' behavior is sensitive to } \\
\text { weather }\end{array}$ & $\begin{array}{l}\text { Roca etal. (2013), Morgenthal and Hallermann (2014), } \\
\text { Siebertand Teizer(2014), Bulgakov etal. (2015), Jordan } \\
\text { (2015), Ka,cuni,cet al. (2016), Wang et al. (2016) }\end{array}$ \\
\hline $\begin{array}{l}\text { Organizational } \\
\text { barriers }\end{array}$ & $\begin{array}{l}\text { Acquisition, setup, operating, } \\
\text { and maintenance costs }\end{array}$ & $\begin{array}{l}\text { Liu etal. (2014), Opfer and Shields (2014), Siebertand } \\
\text { Teizer (2014), Ka,cuni,cet al. (2016), Kim et al. (2016), } \\
\text { Kumar et al. (2016) }\end{array}$ \\
\hline & Management and owner support & Kim et al. (2016) \\
\hline
\end{tabular}


operations should have an emergency fail-safe plan. The GPS-based flight positioning system of the RPAs can also engender flight inaccuracy when operating within confined and/or indoor areas (Siebert and Teizer, 2014; Reagan et al., 2016). Similarly, height and speed variations of the flights can also cause inaccuracy within the RPAs positioning system (Li et al., 2016).

Surveying a vast area requires a logical way of capturing a sufficientnumber of images

and, therefore, efficient flight path planning is essential (Irizarry and Costa, 2016). Flight path planning represents a major concern in large terrain mappings and 3D terrain reconstruction (Torres et al., 2016) and requires careful consideration prior to RPA flights. Using RPAs for site safety inspections and modeling the as-is condition of sites also faces challenges due to the inability of RPAs to track the location of onsite dynamic objects like mobile off-highway plant and machinery (such as: rough terrain telescopic handlers, crawler cranes and dump trucks) (Kim et al., 2016). This inability limits safety inspection features of RPAs to static equipment such as generators. A potential solution is flying several RPAs simultaneously to cover the entire site, though it still requires a carefully planned path, to avoid clashes betweenRPAs.

As illustrated in Table 1, images taken by RPAs can have low resolutions that provide insufficient details for modeling and analyses purposes; this represents a significant barrier to the adoption of RPAs for these activities. This largely occurs due to the erroneous selection of flight altitude and speed (Li et al., 2016) or mounted camera's resolution rate (Wang et al., 2016). Surveying procedures by laser scanner devices mounted on RPAs also experience a mixed pixel phenomenon, thus reducing the usefulness of the data collected (Hamledari et al., 2017a). The problem occurs when the scanner faces reflective materials which are prevalent in construction sites like reflexive glass or galvanized steel components, leading to difficulties in the use of collected data with extra effort needed for the subsequent modeling process (Hamledari et al., 2017a). RPAs flying system can also cause vibrations that can adversely affect image qualities (Reagan et al., 2016). The rotation of RPAs propellers causes some turbulence as a result of the air movement across the propellers which is known as wake interaction (Kim et al., 2017). Ellenberg et al. (2016a) suggest that placing the camera upon a vibration dampening system at the bottom of RPA, instead of placing it on a gimbal, will reduce the vibration levels $\left(\mathrm{m} / \mathrm{s}^{2}\right)$. Kim et al. (2017) propose optimizing the aerodynamics of RPAs through modifying the affecting forces (thrust, drag, lift and weight) alongside the RPAs center of gravity.

The load carriage capacity of RPAs is significantly lower than manned aircrafts and helicopters. This limits the aerial capabilities of the RPAs and their capacity in carrying various types of cameras for aerial photography (Eschmann et al., 2012; Liu et al., 2014; Morgenthal and Hallermann, 2014; Siebert and Teizer, 2014; Ellenberg et al., 2016a; Leahy et al., 2016). Most RPAs also have limited storage capacity in terms of power. Battery types commonly used include lithium polymer (LiPo), nickel metal hydride (NiMH) and nickel cadmium (NiCd) batteries that provide circa 30-min flight duration (Drone Omega, 2017). This restriction is significant where long-time flights are required (Hassanalian and Abdelkefi, 2017). Several studies have argued that short battery capacity is an obstacle to further use of remote aerial vehicles' potentials in the industry (Irizarry et al., 2012; Morgenthal and Hallermann, 2014; Opfer and Shields, 2014; Munoz-Morera et al., 2015; Ellenberg et al., 2016b; Fang et al., 2016; Kim et al., 2016; Leahy et al., 2016). Power shortage is also a reason for loss of data during transferring of images or videos (Moud and Gheisari, 2016; Torres et al., 2016; Yang and Nagarajaiah, 2017). LiPo batteries, the most common battery type in the RPA industry, are very easily damaged and their electrolyte is volatile and extremely flammable. LiPo batteries, therefore, are described as one of the most 
dangerous batteries, and their incorrect use can lead to fire or even explosion (Droneblog Editor, 2016).

From an operator's perspective, the ease of RPA use is an imperative factor. Kim et al. (2016) found that the user-friendliness of the RPAs operating interface is a significantly important factor for inspection tasks, as well as having interactive functions to hover around the focused area to provide real-time videos/photos. This is, however, a lesser problem for surveying tasks and current interfaces are highly user friendly.

\section{Restrictive regulatory environment}

Given the rapid growth of RPAs usage throughout the aviation industry, there is a need for an aviation traffic settlement to avoid in-flight collisions. For example, Clothier et al. (2015) and Jordan (2015) note the significantly elevated risk of collision between high-altitude flying RPAs and conventionally piloted aircraft - such could be catastrophic for passenger safety. According to the Australian Transport Safety Bureau (ATSB), 48 per cent of RPA unsafe flight reports from January 2012 to June 2017 included close encounters with manned aircrafts, and 23 per cent were collisions with terrain, where remaining ones were related to the loss of control issues (ATSB, 2017). Post-analysis studies have shown that a majority of RPAs accidents occurs due to system failures, due to equipment problems (Wild et al., 2017). These problems, hence, can be attributed to the lack of a proper collision avoidance system in commercial RPAs (Morgenthal and Hallermann, 2014). With this issue in mind and with public safety as the top priority, RPA operations internationally have been subject to restrictive regulatory frameworks (Morgenthal and Hallermann, 2014; Blinn and Issa, 2016; Herrmann, 2016; Kacunic et al., 2016; Kim et al., 2016). Amendments to Part 101 of the Civil Aviation Safety Regulations 1998 of Australia commenced on September 29, 2016, and restricts commercial flights with no need for licensed pilots to RPAs under $2 \mathrm{~kg}$. Also, anyone operating RPAs under this category must notify the Civil Aviation Safety Authority (CASA) at least five working days before the first flight and follow the standard operating conditions (CASA, 2018), which arequite restrictive for typical construction activities.

The CASA requires the RPA remote pilot license (RePL) and also remote operator certificate (ReOC) for any operation that does not fall within the above conditions, namely, those termed as "excluded RPA" (CASA, 2018). Therefore, construction tasks, typically beyond the "excluded RPA" conditions, require licensed operators on construction sites. Blinn and Issa (2016) importantly highlight the need for highly skilled personnel to operate RPAs due to construction site complexities and layout. This incurs additional cost on projects and creates concerns related to the cost of employing a certified operator (Irizarry et al., 2012; Boudreau, 2016; Kim et al., 2016). Opfer and Shields (2014) suggest subcontracting the task to an external firm specialized in RPAs, although this can reduce the agility of the main contractor to perform this task when needed.

Ownership, maintenance and use of RPAs in construction create legal liability for the

contractor. Property owners and contractors will require an insurance provider to cover the risks associated with RPAs operations (Herrmann, 2016). In Australia, RPAs insurances are available as: hull cover that covers loss and damages occurred to the RPA itself and liability that covers damage to third parties/properties caused by RPA operation (Thelander, 2017). However, Boudreau (2016) states that contractors should not assume that insurance will fully recover the suffered damage. Pilots of RPAs are usually unknown to many, and identifying who is liable for the flight can be problematic. According to Lidynia et al. (2017), the public is extremely concerned about pilot anonymity breaches of privacy without their permission. Similarly, on-site construction workers feel uncomfortable about being monitored by an unknown person (Boudreau, 2016; Costa et al., 2016; Herrmann, 2016; 
Kim et al., 2016). The perception of using RPAs for commercial purposes is quite recent and many people are unfamiliar with the technology and concomitant safety issues (Clothier et al., 2015). Although flying RPAs in populated areas is restricted by the aviation safety regulations in different countries, palpable concerns still remain (Opfer and Shields, 2014; Siebert and Teizer, 2014; Boudreau, 2016; Ka,cuni,cet al., 2016; Kim et al., 2016). The reasons for the public's disquiet are myriad, but a notable lack of emergency plans further exacerbates matters considerably (Kim et al., 2016). These issues could be solved through a well-established communication protocol to advertise stringent measures implemented to protect the public (Anastasios et al., 2018).

\section{Site-related problems}

RPAs are proven efficient in detection and measurement of structural health of building elements (Ellenberg et al., 2016b, 2016a, Moud and Gheisari, 2016; Reagan et al., 2016). However, RPAs operating on construction projects elevate safety risks for on-site workers, particularly when a close-up view for structural health monitoring is required (Costa et al., 2016). Indeed, Phua (2016) illustrated that construction workers have a significant propensity for risk-taking. Therefore, to avoid collisions between workers and RPAs, a tiered system of safety control measures must be implemented. This could include: operating in areas where workers have restricted or no access, using "engineered-out" solutions such as alarming systems and/or deploying safe systems of working such as using an aircraft information map and a traffic controlling system on site (Irizarry and Costa, 2016; Kim et al., 2016). In fact, construction site safety monitoring and management through use of RPAs have received significant academic attention (Golizadeh et al., 2018; Li and Liu, 2018); however, safety concerns must be properly addressed in the risk management of actual projects - taking into consideration the fact that operating RPAs would unexpectedly interfere with project activities. For example, Costa et al. (2016) highlight possible workers' distraction while RPAs are flying in close proximity and the implications this has upon reduced concentration, safety and productivity.

\section{Weather}

Commercial RPAs are significantly low weight and can be affected by extreme weather conditions (Bulgakov et al., 2015; Ka,cuni,c et al., 2016). High winds (>30 km/h) limit control and reduce flight time due to overuse of battery power to maintain position. Stronger winds can blow the RPA off course into objects and/or push the aircraft beyond areas of recovery (Jordan, 2015). The quality of images is also reduced as wind causes RPAs to vibrate, thus

affecting performance of the attached camera (Siebert and Teizer, 2014). Reduced quality of images is a major concern in structural health monitoring where the accurate measurement of the displacements is required (Morgenthal and Hallermann, 2014). Operation of RPAs in foggy and snowy weather is also difficult as operator visibility reduces from the standing point, as well as the first-person view (Wang et al., 2016). In addition, Roca et al. (2013) describe how lighting direction can adversely affect images taken. Typical commercial RPAs are also not waterproof, and the desired photo quality would not be affordable in such weather (Jordan, 2015).

Cold temperatures make batteries lose charge faster, while heat is also problematic to engines and propellers, because RPAs typically produce quite a bit of heat on their own; hence, heat can put unnecessary wear and tear on batteries, computers and engines. 


\section{Organizational barriers}

Acquisition, setup, operating and maintenance costs of RPAs at the current state are relatively high (Opfer and Shields, 2014; Kim et al., 2016; Kumar et al., 2016). There are also major risks in using RPAs such as a loss of asset in case of breakdown or crash of aircraft (Ka,cuni,c et al., 2016). A study by Siebert and Teizer (2014) shows that the running costs of flying systems (such as airships, fixed-winged aircrafts and helicopters) for surveying tasks in earthwork projects are relatively higher than RPAs. RPAs at their current state are still evolving beyond their military origin to become powerful business tools (Goldman Sachs, 2016) and require further customizations for civil engineering tasks - where the costs of customizations can be high (Liu et al. (2014). Considering the growing number of RPAs throughout the industry, there is an opportunity in the future for the mass production of specific/bespoke RPAs for construction usage that would reduce their costs. Kim et al. (2016) argue that lack of support from owners and project managers is a major barrier for using RPAs in the construction sites, one explanation being the fear of additional liabilities incurred. This barrier would require a comprehensive understanding of the benefits and risks that RPAs bring to site operations.

\section{Discussion}

Research and industry reports have acknowledged the existence of barriers that hamper the wider adoption of RPAs in the construction context (Dupont et al., 2017; McCabe et al., 2017; McMinn, 2017; Zhou and Gheisari, 2018). With this in mind, this study provides original insight by taking the argument about the barriers to the next level. Raising awareness of the nature of these barriers, exploring and providing a typology of them are among the major contributions of this study. Moreover, addressing the identified barriers from a broader perspective through proposing remedial solutions based on the TTF lens and lessons learned in other industries make the study the first of its kind on the topic.

\section{RPAs: an under-fit match for construction activities}

The main purpose of using the TTF lens is to identify areas in need of change in terms of the technology or its environment (Samaradiwakara and Gunawardena, 2014). Figure 2 conceptualizes the nature of barriers identified within extant literature. A major part of barriers to RPA adoption on construction projects have roots in technical difficulties - the incapability of RPAs technology to deal with the requirements of the tasks. Indeed, inefficient flight paths, lack of accuracy, lack of functionality in consuming information from other devices and actors, limited flight duration, etc. can all be attributed to the immature technology of RPAs. This insight is in line with industry reports that call for more technologically capable aircrafts to make RPAs a viable solution for businesses (Morrison, 2016). The restrictive regulatory environments enforced, problems with inclement weather and the site-related problems facing construction companies in using RPAs also have roots in the immature technology of RPAs (Anastasios et al., 2018). That is, the restrictive regulatory environment and problems on construction sites largely stem from the intention to avoid collision risks with manned aircrafts, objects on sites and workers (John et al., 2018). These concerns mostly stem from the fact that RPAs technology in automatically sensing, detecting and avoiding fixed and moving objects and obstacle can be described as immature when compared to manned aerial vehicle (Zhahir et al., 2016). In fact, safety issues and collision problems with RPAs on construction projects are predominantly rooted in the deficiency of their collision avoidance technology (John et al., 2018). 


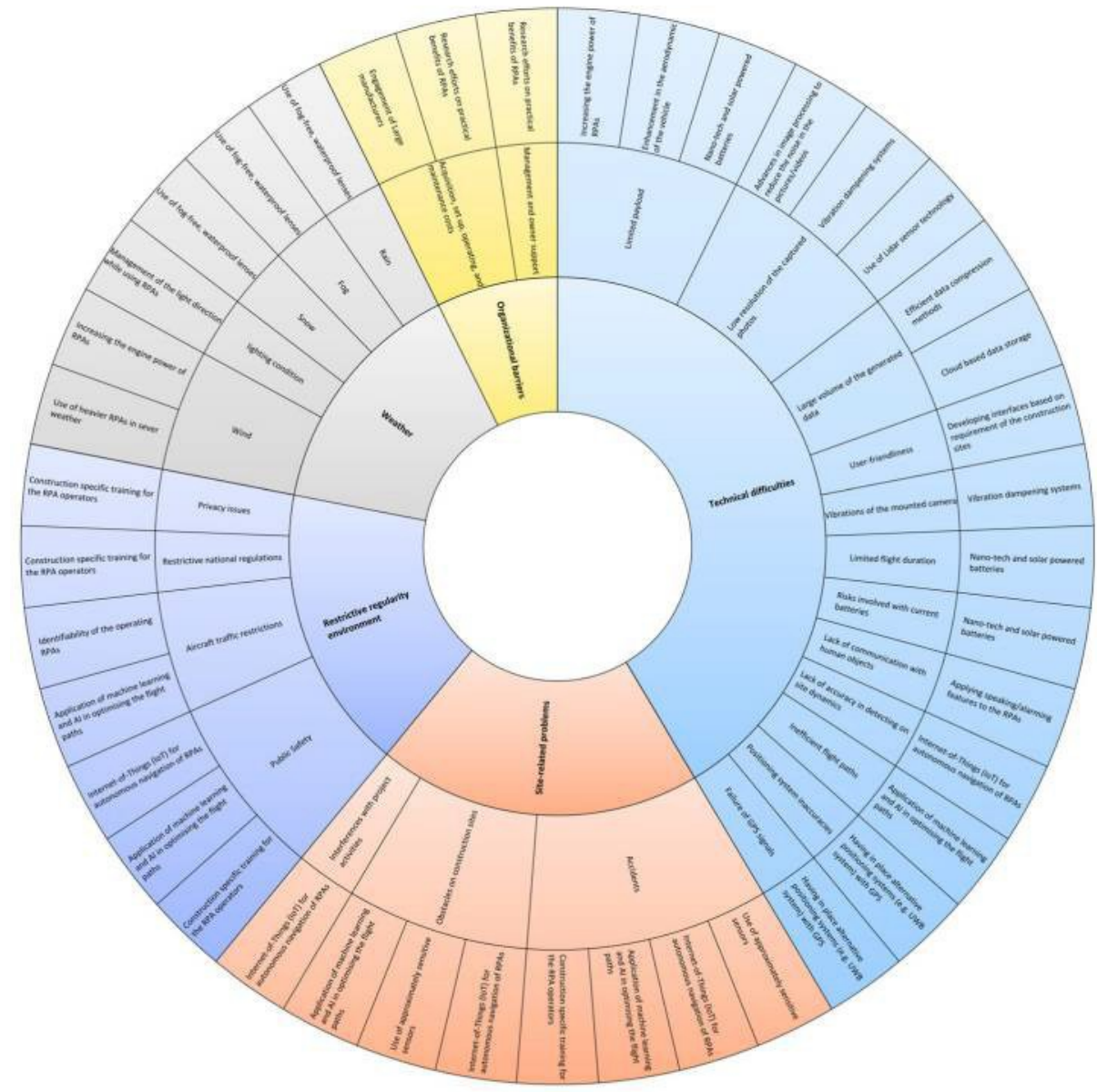

Note: The inner layer shows the typology of barriers, the layer in the middle describes the barriers and the outer layer contains the description of enablers

Figure 2. Model of identified barriers and proposed enablers

The primary challenge, therefore, is to improve the collision avoidance technology in RPAs. Given the limitations of payloads, an effective collision avoidance technology is still missing. That is, under current circumstances, viable collision avoidance technology must be lightweight, small in size and consume low power, hence limited in efficiency (Zhahir et al., 2016).

From the perspective of TTF, the technology utilized in RPAs can be described as under- fit against the background of construction project requirements, according to the definition by Junglas et al. (2008). This is a dissenting viewpoint, given that previous studies have largely focused upon public acceptance, privacy concerns and negative perceptions as being the key barriers to the widespread use of RPAs (Clothier et al., 2015; Rao et al., 2016; McPartland, 2017). This study, nevertheless, points to another source of problem, namely, immature 
technology as the driving barrier to presenting RPAs as an under-fit match for construction activities.

\section{Barriers and proposed enablers}

With the above in mind, Figure 2 presents the identified barriers along with the potential enablers proposed to tackle these. While these solutions are not validated on real-life cases, they are adapted from the literature and recommendations by industry experts and RPA operators reflected - as widely reported via industry discussion forums, weblogs and websites devoted to RPAs.

As illustrated in Figure 2, storage of big data collected by RPAs could be shifted to cloud storage which provides sufficient space with live accessibility for on-site and off-site users (Jiao et al., 2013). Alternatively, data can be compressed to lower capacities; hence, the main challenge with this approach is the development of an appropriate compression method that does not hemorrhage data (Yang and Nagarajaiah, 2017).

RPAs are expected to work in GPS-denied environments such as tunnels or close to heavy steel structures such as bridges. To avoid adverse consequences related to the loss of RPAs position requires the utilization of alternative local positioning systems like ultra- wideband (UWB) in tandem with GPS (Tiemann et al., 2015). Installation of a UWB module on RPAs enables the aircraft to actively send location tracking data to fixed UWB receivers at certain positions (anchors), thus overcoming the limitations of utilizing GPS: blocked line- of-sights, failure in indoor, forest or urban environments (Guo et al., 2016).

Having an alarming/speaking function integral within an RPA design also allows it to communicate with out-reach people, who are in close distance to the RPAs. As argued by Irizarry et al. (2012), such a system improves the productivity of the RPAs on construction sites and allows the safer use of RPAs for real-time site inspections during the times the site is populated withworkers.

RPAs are expected to be operational full time on construction sites, and that requires a fundamental solution to low battery capacities. Recent advancements in nanotechnology have found new battery types such as those produced by A123 Systems LLC, M-Phase Technologies and HE3DA that have greater power storage capacities and are already being used in other products (Wong and Dia, 2017). Besides, advances in nanotechnology batteries can be a solution to many drawbacks with batteries currently used in the RPA industry (Wong and Dia, 2017). Photovoltaics could also be used to tackle the issues with current batteries, as well as their data management systems (Rojas et al., 2015). Having more power on-board enables longerduration operations and makes RPAs capable of carrying heavier equipment with more accuracy and efficiency (Corrigan, 2018a). This, however, relies also on parallel development of lightweight equipment for RPAs that can endure the flying condition.

As illustrated in Figure 2, use of machine learning and Al are proposed as remedial solutions that can resolve the current deficiencies of RPAs through a variety of scenarios. These can facilitate reducing the flight durations by designing and optimizing the flight paths (Torres et al., 2016). Al can also be implemented for faster and effective image processing and model development (Ofli et al., 2016; Cha et al., 2017). Al can also assist in making RPAs safer and reduce risks to the public through trying various trajectories, experiencing crashes into objects and creation of a data set to capture the various modes and ways in which RPAs crash or collide. This self-supervised mechanism is proven effective in navigating RPAs in extremely cluttered environments with dynamic objects and even humans (Gandhi et al., 2017) - conditions similar to that of construction sites. Another approach to reduce the risk of unsafe proximity of RPAs with construction equipment and workers can be using proximity sensors 
and Internet of Things (IOT) for autonomous navigation of RPAs around construction sites (Palossi et al., 2018). As practiced by Teizer and Cheng (2015), real-time location tracking systems (RTLS) can spot the location of workers, off- highway plant and equipment and produce warnings in unsafe proximity cases.

Construction-related operations require an understanding of the nature of construction activities, and hence, particular training courses can enhance the effectiveness and safety of flights (McMinn, 2017; Ayemba, 2018). Further, proximity detecting sensors can be helpful in this regard, as they can prevent unpleasant clashes between RPAs and human or site objects (Teizer and Cheng, 2015; Corrigan, 2018b).

\section{Conclusion}

RPAs represent an emerging technological innovation that will revolutionize the construction industry, given its potential in improving productivity, enhancing site logistics, accelerating project progress and increasing site safety. Construction companies, however, face a wide range of barriers to adopt RPAs on site. This research represents the first attempt to provide a succinct and clear picture of these barriers and, consequently, breaks new grounds in identifying and conceptualizing them from extant literature. The study also provides insight into the major source of barriers that hinder the widespread use of RPAs in construction projects, in dialogue with the TTF theory. There is need for a paradigm shift in focus from societal impacts and RPAs acceptance (by the public) toward addressing the technological deficiencies of RPAs, particularly those pertaining safety matters like collision avoidance systems. It is noted that RPAs at the current stage are under-fit for the construction sector, and majority of the technical barriers root in the operational systems of the RPAs. This can be addressed as a crossdisciplinary issue of the construction and aviation industries, requiring R\&D activities to address the problems. The paper is also the first attempt in identifying potential enablers to barriers identified in the existing literature on RPAs, visualized in the form of a graphical model. The model demonstrates that looking toward future advances, RPAs are not considered as separate data providers and disconnected from the rest of construction activities. Future RPAs are expected to be: intelligent and programmed to predict risks (Al), in constant connection to all equipment and resources around them (IOT), empowered by nanotechnology batteries, prepared to operate in severe environmental conditions and operated under more accurate positioning systems. Despite the focus of the study on the construction context, the findings carry implications for RPA manufacturers and technology companies. That is, the model of barriers can be regarded as collected feedback to provide insight into the requirements of construction companies in terms of the capabilities and functions of ideal RPAs to perform construction activities.

Despite the contributions above, the research undertaken has three limitations noteworthy of mentioning. First, given that the findings come from a literature review, they remain theoretical and require validation through exposure to empirical data and tested on real-life projects. Second, the regulatory environment is analyzed from a predominantly Australian perspective and, hence, discussions on this area might not be directly transferrable to other regulatory contexts. Third, the study intends to provide a picture of barriers and their corresponding enablers in abstract concepts, and as such, might lack precision for direct application on construction projects. Certainly, the barriers, enablers and suggestions presented in this study are subject to further review from RPA operators, aviation authorities and manufacturers to complete any missing items that the authors have not identified. That said, it is envisaged that the work presented here is the starting point to 
move toward a widely accepted framework to overcome the barriers, to make the RPA market sustainable. These limitations, hence, provide fertile grounds for future research and much-needed wider academic debate. Future studies can also delve into the nature of each identified barrier and attempt to provide remedial solutions for each item. The findings of the study also warrant further research into improving the collision avoidance technology used in RPAs, given the conditions of their application on construction sites. In addition, given the large market size for RPAs in the construction industry, research into the design of customized RPAs for construction purposes might be another area of investigation offered through the findings presented here.

\section{References}

Alsafouri, S. and Ayer, S.K. (2018), "Review of ICT implementations for facilitating information flow between virtual models and construction project sites", Automation in Construction, Vol. 86, pp. 176-189.

Anastasios, P., Nektarios, K. and Mikela, C.M. (2018), "Hazard analysis and safety requirements for small drone operations: to what extent do popular drones embed safety?", Risk Analysis, Vol. 38 No. 3, pp. 562584, doi: 10.1111/risa.12867.

Antioco, M. and Kleijnen, M. (2010), "Consumer adoption of technological innovations: effects of psychological and functional barriers in a lack of content versus a presence of content situation". European Journal of Marketing, Vol. 44 Nos 11/12, pp. 1700-1724, doi: 10.1108/03090561011079846.

ATSB (2017), "A safety analysis of remotely piloted aircraft systems 2012 to 2016: a rapid growth and safety implications for traditional aviation", Australian Transport Safety Bureau, available at: www.atsb.gov.au/publications/2017/ar-2017-016/ (accessed 22 June 2018).

Ayemba, D. (2018), "Utilizing drone technology in construction", available at: https:// constructionreviewonline.com/2018/03/drones-in-construction/ (accessed 18 June 2018).

Blinn, N. and Issa, R.R.A. (2016), "Feasibility assessment of unmanned aircraft systems for construction management applications: construction research congress 2016: old and new construction technologies converge in historic San Juan", Proceedings of the 2016 Construction Research Congress, CRC, pp. 25932603, doi: 10.1061/9780784479827.258.

Boudreau, T. (2016), "Six questions to ask your construction clients before they begin using drones", ENR (Engineering News-Record), Vol. 277 No. 13, pp. 1-2.

Bulgakov, A., Evgenov, A. and Weller, C. (2015), "Automation of 3D building model generation using quadrotor", in Hajdu, M. and Skibniewski, M.J. (Eds), Creative Construction Conference 2015, Selected Papers, Elsevier Science Bv, Amsterdam.

Butler, L. and Visser, M.S. (2006), "Extending citation analysis to non-source items", Scientometrics, Vol. 66 No. 2, pp. 327-343, doi: 10.1007/s11192-006-0024-1.

Canis, B. (2015), Unmanned Aircraft Systems (UAS): Commercial Outlook for a New Industry, Congressional Research Service, Washington, DC.

CASA (2016), Civil Aviation Safety Regulations Part 101, The Civil Aviation Safety Authority, Canberra, available at: www.legislation.gov.au/Details/F2017C00742/Download (accessed 18 June 2018).

CASA (2018), "Flying over your own land - excluded RPA", Civil Aviation Safety Authority, available at: www.casa.gov.au/aircraft/standard-page/excluded-remotely-piloted-aircraft-flying-over-yourown-land (accessed 28 June 2018).

Cha, Y.J., Choi, W. and Büyüköztürk, O. (2017), "Deep learning-based crack damage detection using convolutional neural networks", Computer-Aided Civil and Infrastructure Engineering, Vol. 32 No. 5, pp. 361378. 
Clarke, R. (2014a), "The regulation of civilian drones' impacts on behavioural privacy", Computer Law and Security Review, Vol. 30 No. 3, pp. 286-305.

Clarke, R. (2014b), "Understanding the drone epidemic", Computer Law and Security Review, Vol. 30 No. 3, pp. 230-246.

Clothier, R.A., Greer, D.A., Greer, D.G. and Mehta, A.M. (2015), "Risk perception and the public acceptance of drones", Risk Analysis, Vol. 35 No. 6, pp. 1167-1183.

Cole, H. Creech, J. (2016), "Drones in construction: beyond pictures. capturing and exploring actionable data", Autodesk University, available at: http://aucache.autodesk.com/au2016

Corrigan, F. (2018a), "12 top lidar sensors for UAVs and so many great uses”, available at: www. dronezon.com/learn-about-drones-quadcopters/best-lidar-sensors-for-drones-great-uses-for-lidar- sensors/ (accessed 18 June 2018).

Corrigan, F. (2018b), "Top collision avoidance drones and obstacle detection explained", available at: www.dronezon.com/learn-about-drones-quadcopters/top-drones-with-obstacle-detection- collisionavoidance-sensors-explained/ (accessed 18 June2018).

Costa, D.B., De Melo, R.R., S.Álvares, J., S. and Bello, A., A. (2016), "Evaluating the performance of unmanned aerial vehicles for safety inspection", IGLC 2016 - 24th Annual Conference of the International Group for Lean Construction, Boston, MA, pp. 23-32.

Dishaw, M.T. and Strong, D.M. (1998), "Supporting software maintenance with software engineering tools: a computedtask-technologyfit analysis", Journalof Systems and Software, Vol. 44 No. 2, pp. 107-120.

Dishaw, M.T. and Strong, D.M. (1999), "Extending the technology acceptance model with tasktechnology fit constructs", Information and Management, Vol. 36 No. 1, pp. 9-21.

Drone Omega (2017), “The advanced quadcopter battery guide”, available at: www.droneomega.com/ quadcopter-battery-guide/ (accessed 3 June 2018).

Droneblog Editor (2016), “LiPo vs intelligent: which battery is best?”, Droneblog.com (C) 2018, available at: www.droneblog.com/2016/08/05/lipo-vs-intelligent-which-battery-is-best/ (accessed 22 June 2018).

Dupont, Q.F.M., Chua, D.K.H., Tashrif, A. and Abbott, E.L.S. (2017), “Potential applications of UAV along the construction's value chain", Procedia Engineering, Vol. 182, pp. 165-173.

Ellenberg, A., Kontsos, A., Moon, F. and Bartoli, I. (2016a), "Bridge deck delamination identification from unmannedaerialvehicle infraredimagery”, Automation in Construction, Vol. 72, pp. 155-165.

Ellenberg, A., Kontsos, A., Moon, F. and Bartoli, I. (2016b), “Bridge related damage quantification using unmanned aerial vehicle imagery", Structural Control and Health Monitoring, Vol. 23 No. 9, pp. 1168-1179, doi: $10.1002 /$ stc.1831.

Eschmann, C., Kuo, C., Kuo, C. and Boller, C. (2012), “Unmanned aircraft systems for remote building inspection and monitoring", 6th European Workshop on Structural Health Monitoring, pp. 1-8.

Fang, Y., Chen, J., Cho, Y.K. and Zhang, P. (2016), “A point cloud-vision hybrid approach for 3D location tracking of mobile construction assets", ISARC 2016 - 33rd International Symposium on Automation and Robotics in Construction, pp. 613-620.

Fishpool, M. (2010), "International military and civilian unmanned aerial vehicle survey", Technical report, Socolofi Research.

Gandhi, D. Pinto, L. and Gupta, A. (2017), “Learning to fly by crashing”, arXiv preprint arXiv:1704.05588.

Gevaert, C.M., Sliuzas, R., Persello, C. and Vosselman, G. (2018), "Evaluating the societal impact of using drones to support urban upgrading projects", ISPRS International Journal of Geo- Information, Vol. 7 No. 3, p. 91.

Gledson, B.J. (2016), "Hybrid project delivery processes observed in constructor BIM innovation adoption", Construction Innovation: information, Process, Management, Vol. 16 No. 2, pp. 229-246. doi: 10.1108/Cl-04-2015-0020. 
Goldman Sachs (2016), "Drones reporting for work", The Goldman Sachs Group, available at: www. goldmansachs.com/our-thinking/technology-driving-innovation/drones/ (accessed 19 September 2017).

Golizadeh, H., Hon, C.K.H., Drogemuller, R. and Reza Hosseini, M. (2018), "Digital engineering potential in addressing causes of construction accidents", Automation in Construction, Vol. 95, pp. 284-295. Goodhue,

D. (1997), "The model underlying the measurement of the impacts of the IIC on the endusers", Journal of the American Society for Information Science, Vol. 48 No. 5, pp. 449-453.

Goodhue, D.L. (1995), "Understanding user evaluations of information systems", Management Science, Vol. 41 No. 12, pp. 1827-1844.

Goodhue, D.L. and Thompson, R.L. (1995), "Task-technology fit and individual performance", MIS Quarterly, Vol. 19 No. 2, pp. 213-236.

Goodhue, D., Littlefield, R. and Straub, D.W. (1997), "The measurement of the impacts of the IIC on the end-users: the survey", Journal of the American Society for Information Science, Vol. 48 No. 5, pp. 454-465.

Greenwood, W.W., Lynch, J.P. and Zekkos, D. (2019), "Applications of UAVs in civil infrastructure", Journal of Infrastructure Systems, Vol. 25 No. 2, p. 04019002.

Guo, K., Qiu, Z., Miao, C., Zaini, A.H., Chen, C.L., Meng, W. and Xie, L. (2016), “Ultra-wideband-based localization for quadcopter navigation", Unmanned Systems, Vol. 4 No. 1, pp. 23-34.

Ham, Y., Han, K.K., Lin, J.J. and Golparvar-Fard, M. (2016), "Visual monitoring of civil infrastructure systems via camera-equipped unmanned aerial vehicles (UAVs): a review of related works", Visualization in Engineering, Vol. 4 No. 1, p. 1, doi: 10.1186/s40327-015-0029-z.

Hamledari, H., McCabe, B. and Davari, S. (2017a), "Automated computer vision-based detection of components of under-construction indoor partitions", Automation in Construction, Vol. 74, pp. 78-94.

Hamledari, H., McCabe, B., Davari, S., Shahi, A., Rezazadeh Azar, E. and Flager, F. (2017b), "Evaluation of computer vision-and 4D BIM-based construction progress tracking on a UAV platform", Proceedings of the CSCE Annual Conference, May 31-June 3, Vancouver.

Han, K.K. and Golparvar-Fard, M. (2017), "Potential of big visual data and building information modeling for construction performance analytics: an exploratory study", Automation in Construction, Vol. 73, pp. 184-198, doi: 10.1016/j.autcon.2016.11.004.

Hassanalian, M. and Abdelkefi, A. (2017), "Classifications, applications, and design challenges of drones: a review", Progress in Aerospace Sciences, Vol. 91, pp. 99-131.

Herlik, E. (2010), "Unmanned aerial vehicles (UAVs) for commercial applications global market and technologies outlook 2011-2016", Technical report, Market Intrel Group LLC.

Herrmann, M. (2016), "Unmanned aerial vehicles in construction: an overview of current and proposed rules", Construction Research Congress 2016: Old and New Construction Technologies Converge in Historic San Juan, pp.588-596.

Hosseini, M.R., Chileshe, N., Zuo, J. and Baroudi, B. (2015), "Adopting global virtual engineering teams in AEC projects: a qualitative meta-analysis of innovation diffusion studies", Construction Innovation: information, Process, Management, Vol. 15 No. 2, pp. 151-179.

Hosseini, M.R., Martek, I., Zavadskas, E.K., Aibinu, A.A., Arashpour, M. and Chileshe, N. (2018), "Critical evaluation of off-site construction research: a scientometric analysis", Automation in Construction, Vol. 87, pp. 235-247.

Imoudu Enegbuma, W., Godwin Aliagha, U. and Nita Ali, K. (2014), "Preliminary building information modelling adoption model in Malaysia: a strategic information technology perspective", Construction Innovation: Information, Process, Management, Vol. 14 No. 4, pp. 408-432. 
Irizarry, J. and Costa, D.B. (2016), "Exploratory study of potential applications of unmanned aerial systems for construction management tasks", Journal of Management in Engineering, Vol. 32 No. 3, doi: 10.1061/(asce)me.1943-5479.0000422.

Irizarry, J., Gheisari, M. and Walker, B.N. (2012), "Usability assessment of drone technology as safety inspection tools", Electronic Journal of Information Technology in Construction, Vol. 17, pp. 194-212.

Jiao, Y., Wang, Y., Zhang, S., Li, Y., Yang, B. and Yuan, L. (2013), “A cloud approach to unified lifecycle data management in architecture, engineering, construction and facilities management: integrating BIMs and SNS", Advanced Engineering Informatics, Vol. 27 No. 2, pp. 173-188.

John, H., Vladimir, M. and Branche, C.M. (2018), "Unmanned aerial vehicles in construction and worker safety", AmericanJournalofIndustrialMedicine, Vol.61No.1,pp.3-10,doi:10.1002/ajim.22782.

Jordan, B.R. (2015), "A bird's-eye view of geology: the use of micro drones/UAVs in geologic fieldwork and education", GSA Today, Vol. 25 No. 7, pp. 50-52.

Junglas, I., Abraham, C. and Watson, R.T. (2008), "Task-technology fit for mobile locatable information systems", Decision Support Systems, Vol. 45 No. 4, pp. 1046-1057.

Ka,cuni,c, D.J., Libri,c, L. and Car, M. (2016), "Application of unmanned aerial vehicles on transport infrastructure network primjena bespilotnih letjelica na prometnoj infrastrukturnoj mreži", Gradjevinar, Vol. 68 No. 4, pp. 287-300, doi: 10.14256/JCE.1382.2015.

Karpowicz, J. (2017a), "Eliminating every barrier for enterprise drone adoption in mining and construction", available at: www.expouav.com/news/latest/eliminating-every-barrier-enterprise- droneadoption-mining-construction/ (accessed 6 April 2018).

Karpowicz, J. (2017b), "Transferring big drone data", available at: www.expouav.com/news/latest/ transferring-big-drone-data/ (accessed 19 June 2018).

Kim, M.S.W., Han, K.H.J. and Heon, J. (2017), "Investigating the aerodynamics of flight for multiple rotor drones", Analysis of Applied Mathematics, Vol. 1, p. 93.

Kim, S., Irizarry, J., Costa., and D, B. (2016), "“Potential factors influencing the performance of unmanned aerial system (UAS) integrated safety control for construction worksites", Construction Research Congress 2016: Old and New Construction Technologies Converge in Historic San Juan, pp. 26142623.

Kumar, V.P., Balasubramanian, M. and Raj, S.J. (2016), "Robotics in construction industry", Indian Journal of Science and Technology, Vol. 9 No. 23.

Kurata, N., Spencer, B.F., Ruiz, A. and Sandoval, M. (2005), "Risk monitoring of buildings with wireless sensor networks", Structural Control and Health Monitoring, Vol. 12 No. 3-4, pp. 315-327.

Landes, T., Boulaassal, H. and Grussenmeyer, P. (2012), "Quality assessment of geometric façade models reconstructed from TLS data", The Photogrammetric Record, Vol. 27 No. 138, pp. 137-154.

Leahy, K., Zhou, D.J., Vasile, C.I., Oikonomopoulos, K., Schwager, M. and Belta, C. (2016), "Persistent surveillance for unmanned aerial vehicles subject to charging and temporal logic constraints", Autonomous Robots, Vol. 40 No. 8, pp. 1363-1378, doi:10.1007/s10514-015-9519-z.

Li, Y. and Liu, C. (2018), "Applications of multirotor drone technologies in construction management", International Journal of Construction Management, Vol. 1, pp. 1-12, doi: 10.1080/ 15623599.2018.1452101.

Li, J.G., Deng, G.Q., Luo, C.W., Lin, Q.Z., Yan, Q. and Ming, Z. (2016), "A hybrid path planning method in unmanned air/ground vehicle (UAV/UGV) cooperative systems", IEEE Transactions on Vehicular Technology, Vol. 65 No. 12, pp. 9585-9596, doi: 10.1109/tvt.2016.2623666.

Lidynia, C., Philipsen, R. and Ziefle, M. (2017), "Droning on about drones-acceptance of and perceived barriers to drones in civil usage contexts", in Savageknepshield, P. and Chen, J. (Eds), Advances in Human Factors in Robots and Unmanned Systems, Springer International Publishing, Cham. 
Liu, P., Chen, A.Y., Huang, Y.N., Han, J.Y., Lai, J.S., Kang, S.C., Wu, T.H., Wen, M.C. and Tsai, M.H. (2014),

"A review of rotorcraft unmanned aerial vehicle (UAV) developments and applications in civil engineering", Smart Structures and Systems, Vol. 13 No. 6, pp. 1065-1094.

Luppicini, R. and So, A. (2016), "A technoethical review of commercial drone use in the context of governance, ethics, and privacy", Technology in Society, Vol. 46, pp. 109-119.

Lynch, J.P. and Loh, K.J. (2006), "A summary review of wireless sensors and sensor networks for structural health monitoring", Shock and Vibration Digest, Vol. 38 No. 2, pp. 91-130.

McCabe, B., Hamledari, H., Shahi, A., Zangeneh, P. and Azar, E.R. (2017), "Roles, benefits, and challenges of using UAVs for indoor smart construction applications", Computing in Civil Engineering, ASCE, Chicago.

McMinn, G. (2017), "Challenges to avoid when launching drone ops at a construction company", available at: https://skyward.io/challenges-to-avoid-when-launching-drone- ops-at-a-constructioncompany/ (accessed 6 April 2018).

McPartland, R. (2017), "Drones in construction", available at: www.thenbs.com/knowledge/drones-inconstruction (accessed 6 April 2018).

Maqbool, S. and Sabeel, U. (2013), "Arising issues in wireless sensor networks: current proposals and future developments", IOSR Journal of Computer Engineering (Engineering), Vol. 8 No. 6, pp. 56-73.

Marchant, G., Allenby, B., Arkin, R.C., Borenstein, J., Gaudet, L.M., Kittrie, O., Lin, P., Lucas, G.R., O'Meara,

R. and Silberman, J. (2015), Handbook of Unmanned Aerial Vehicles, Springer Netherlands, Berlin.

Market Research Store (2012), "Commercial unmanned aerial systems (UAS): market shares, strategies, and forecasts, worldwide, 2012 to 2018", Market Research Store, available at: www. marketresearchstore.com

Melo, R.R.S., d Costa, D.B., Álvares, J.S. and Irizarry, J. (2017), “Applicability of unmanned aerial system (UAS) for safety inspection on construction sites", Safety Science, Vol. 98 No. Supplement C, pp. 174-185.

Mollaoglu, S., Chergia, C., Ergen, E. and Syal, M. (2016), "Diffusion of green building guidelines as innovation in developing countries", Construction Innovation: information, Process, Management, Vol. 16 No. 1, pp. 11-29, doi: 10.1108/Cl-09-2014-0045.

Morgenthal, G. and Hallermann, N. (2014), "Quality assessment of unmanned aerial vehicle (UAV) based visual inspection of structures", Advances in Structural Engineering, Vol. 17 No. 3, pp. 289-302, doi: 10.1260/1369-4332.17.3.289.

Morrison, A. (2016), "Are commercial drones ready for takeoff?", Next in Tech, available at: http:// usblogs.pwc.com/emerging-technology/are-commercial-drones-ready-for-takeoff/ (accessed 7 May 2018).

Moud, H.I. and Gheisari, M. (2016), "Coupling wireless sensor networks and unmanned aerial vehicles in bridge health monitoring systems", ISARC 2016 - 33rd International Symposium on Automation and Robotics in Construction, pp. 267-273.

Müller-Bloch, C. and Kranz, J. (2015), "A framework for rigorously identifying research gaps in qualitative literature reviews", Thirty Sixth International Conference on Information Systems, Fort Worth, Texas, 13-1 December, available at: https://pdfs.semanticscholar.org/7359/ 6c4957deab7c7a3fd1d4261994e47be1508c.pdf

Munoz-Morera, J., Maza, I., Fernandez-Aguera, C.J., Caballero, F. and Ollero, A. (2015), "Assembly planning for the construction of structures with multiple UAS equipped with robotic arms", International Conference on Unmanned Aircraft Systems, ICUAS, pp. 1049-1058, doi: 10.1109/ICUAS.2015.7152396.

Ofli, F., Meier, P., Imran, M., Castillo, C., Tuia, D., Rey, N., Briant, J., Millet, P., Reinhard, F. and Parkan,

M. (2016), "Combining human computing and machine learning to make sense of big (aerial) data for disaster response", Big Data, Vol. 4 No. 1, pp. 47-59. 
Omar, T. and Nehdi, M.L. (2017), "Remote sensing of concrete bridge decks using unmanned aerial vehicle infrared thermography", Automation in Construction, Vol. 83, pp. 360-371.

Opfer, N.D. and Shields, D.R. (2014), “Unmanned aerial vehicle applications and issues for construction”, in 121st ASEE Annual Conference and Exposition.

Pádua, L., Vanko, J., Hruška, J., Adão, T., Sousa, J.J., Peres, E. and Morais, R. (2017), “UAS, sensors, and data processing in agroforestry: a review towards practical applications", International Journal of Remote Sensing, Vol. 38Nos8/10, pp. 2349-2391, doi:10.1080/01431161.2017.1297548.

Palossi, D., Loquercio, A., Conti, F., Flamand, E., Scaramuzza, D. and Benini, L. (2018), “Ultra low power DeepLearning-powered autonomous nano drones", arXiv Preprint arXiv, 1805.01831.

Pärn, E.A. and Edwards, D.J. (2017), “Conceptualising the FinDD API plug-in: a study of BIM-FM integration", Automation in Construction, Vol. 80, pp. 11-21.

Phua, F. (2016), “Does the built-environment industry attract risk-taking individuals?", Construction Management and Economics, Vol. 35, pp. 1-11.

Rakha, T., Liberty, A., Gorodetsky, A., Kakillioglu, B. and Velipasalar, S. (2018), "Heat mapping drones: an autonomous computer-vision-based procedure for building envelope inspection using unmanned aerial systems (UAS)", Technology/Architecture Design, Vol. 2 No. 1, pp. 30-44, doi: 10.1080/24751448.2018.1420963.

Rao, B., Gopi, A.G. and Maione, R. (2016), "The societal impact of commercial drones", Technology in Society, Vol. 45 No. Supplement C, pp. 83-90.

Reagan, D., Sabato, A., Niezrecki, C., Yu, T. and Wilson, R. (2016), “An autonomous unmanned aerial vehicle sensing system for structural health monitoring of bridges", Proceedings of SPIE - The International Society for Optical Engineering, doi: 10.1117/12.2218370.

Roca, D., Laguela, S., Diaz-Vilarino, L., Armesto, J. and Arias, P. (2013), "Low-cost aerial unit for outdoor inspection of building facades", Automation in Construction, Vol. 36, pp. 128-135, doi: 10.1016/j. autcon.2013.08.020.

Rogers, E.M. (2010), Diffusion of Innovations, Simon and Schuster, New York, NY.

Rojas, A.J., Gonzalez, L.F., Motta, N. and Villa, T.F. (2015), “Design and flight testing of an integrated solar powered UAV and WSN for remote gas sensing", Aerospace Conference, IEEE, IEEE, pp. 1-10.

Samaradiwakara, G. and Gunawardena, C. (2014), "Comparison of existing technology acceptance theories and models to suggest a well improved theory/model", International Technical Sciences Journal, Vol. 1 No. 1, pp. 21-36.

Schlauderer, S., Overhage, S. and Weidinger, J. (2016), "New vistas for firefighter information systems? Towards a systematic evaluation of emerging technologies from a Task-Technology fit perspective", 49th HI International Conference on System Sciences (HICSS), IEEE, Koloa, HI, 5-8 January, pp. 178-187, doi: 10.1109/HICSS.2016.30.

Seo, J., Han, S., Lee, S. and Kim, H. (2015), "Computer vision techniques for construction safety and health monitoring", Advanced Engineering Informatics, Vol. 29 No. 2, pp. 239-251, available at: https://doi.org/10.1016/j.aei.2015.02.001

Serrano, N.E. (2011), Autonomous Quadrotor Unmanned Aerial Vehicle for Culvert Inspection, MA Institute of Technology, MA.

Siebert, S. and Teizer, J. (2014), "Mobile 3D mapping for surveying earthwork projects using an unmanned aerial vehicle (UAV) system", Automation in Construction, Vol. 41, pp. 1-14, doi: 10.1016/j.autcon.2014.01.004.

Stöcker, C., Bennett, R., Nex, F., Gerke, M. and Zevenbergen, J. (2017), "Review of the current state of UAV regulations", Remote Sensing, Vol. 9 No. 5, p. 459.

Teizer, J. (2015), "Status quo and open challenges in vision-based sensing and tracking of temporary resources on infrastructure constructionsites", Advanced Engineering Informatics, Vol. 29 No. 2, pp. 225-238. 
Teizer, J. and Cheng, T. (2015), "Proximity hazard indicator for workers-on-foot near miss interactions with construction equipment and geo-referenced hazard areas", Automation in Construction, Vol. 60, pp. 58-73.

Thelander, C. (2017), "How drones and UAVs are changing the insurance industry", available at: www. canstar.com.au/home-insurance/home-and-contents-insurance/the-future-of-insurance-claims-is- drones/

Tiemann, J., Schweikowski, F. and Wietfeld, C. (2015), “Design of an UWB indoor-positioning system for UAV navigation in GNSS-denied environments", Indoor Positioning and Indoor Navigation (IPIN), 2015 International Conference on, IEEE, pp. 1-7.

Torres, M., Pelta, D.A., Verdegay, J.L. and Torres, J.C. (2016), "Coverage path planning with unmanned aerial vehicles for 3D terrain reconstruction", Expert Systems with Applications, Vol. 55, pp. 441-451, doi: 10.1016/j.eswa.2016.02.007.

Vacca, G., Dessì, A. and Sacco, A. (2017), "The use of nadir and oblique UAV images for building knowledge", ISPRS International Journal of Geo-Information, Vol. 6 No. 12, p. 393.

Wang, L., Chen, F.L. and Yin, H.M. (2016), “Detecting and tracking vehicles in traffic by unmanned aerial vehicles", Automation in Construction, Vol. 72, pp. 294-308, doi: 10.1016/j.autcon.2016.05.008.

Wild, G., Gavin, K., Murray, J., Silva, J. and Baxter, G. (2017), "A post-accident analysis of civil remotelypiloted aircraft system accidents and incidents", Journal of Aerospace Technology and Management, Vol. 9 No. 2, pp. 157-168.

Wong, K. and Dia, S. (2017), "Nanotechnology in batteries", Journal of Energy Resources Technology, Vol. 139 No. 1, p. 014001.

Yang, Y.C. and Nagarajaiah, S. (2017), "Robust data transmission and recovery of images by compressed sensing for structural health diagnosis", Structural Control and Health Monitoring, Vol. 24 No. 1, doi: 10.1002/stc.1856.

Zaloga, S.J. (2011), Unmanned Aerial Vehicles: Robotic Air Warfare 1917-2007, Bloomsbury Publishing, London.

Zhahir, A., Razali, A. and Ajir, M.M. (2016), "Current development of UAV sense and avoid system", IOP Conference Series: Materials Science and Engineering, IOP Publishing, p. 012035.

Zhou, S. and Gheisari, M. (2018), "Unmanned aerial system applications in construction: a systematic review", Construction Innovation,Vol.18No.4,pp.453-468,doi:10.1108/Cl-02-2018-0010.

Zigurs, I. and Buckland, B.K. (1998), "A theory of task/technology fit and group support systems effectiveness", MIS Quarterly, Vol. 22 No. 3. 